\title{
An amplitude-based characteristic parameter extraction algorithm for cerebral edema detection based on electromagnetic induction
}

\author{
Jingbo Chen ${ }^{1}$, Gen Li2 ${ }^{*}$, Huayou Liang ${ }^{3}$, Shuanglin Zhao ${ }^{1}$, Jian Sun ${ }^{1}$ and Mingxin Qin ${ }^{1 *}$ (D)
}

\author{
${ }^{*}$ Correspondence: \\ ligen1990@cqut.edu.cn: \\ qmingxin@tmmu.edu.cn \\ ${ }^{1}$ College of Biomedical \\ Engineering, Third Military \\ Medical University (Army \\ Medical University), \\ Chongqing, China \\ ${ }^{2}$ School of Pharmacy \\ and Bioengineering, \\ Chongqing University \\ of Technology, Chongqing, \\ China \\ Full list of author information \\ is available at the end of the \\ article
}

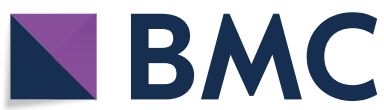

( ) The Author(s) 2021. This article is licensed under a Creative Commons Attribution 4.0 International License, which permits use, sharing, adaptation, distribution and reproduction in any medium or format, as long as you give appropriate credit to the original author(s) and the source, provide a link to the Creative Commons licence, and indicate if changes were made. The images or other third party material in this article are included in the article's Creative Commons licence, unless indicated otherwise in a credit line to the material. If material is not included in the article's Creative Commons licence and your intended use is not permitted by statutory regulation or exceeds the permitted use, you will need to obtain permission directly from the copyright holder. To view a copy of this licence, visit http://creativecommons.org/ licenses/by/4.0/. The Creative Commons Public Domain Dedication waiver (http://creativecommons.org/publicdomain/zero/1.0/) applies to the data made available in this article, unless otherwise stated in a credit line to the data.
Conclusion: The proposed Ab-CPE algorithm is suitable for multi-frequency characteristic analysis. Combined with this algorithm, the electromagnetic induction method has an excellent performance on the detection and monitoring of cerebral edema.

Keywords: Cerebral edema, Electromagnetic induction, Ab-CPE algorithm, Multifrequency characteristic analysis

\section{Background}

Cerebral edema, which can be defined as the abnormal increase and accumulation of intracranial fluid, is a common condition secondary to stroke and traumatic brain injury (TBI). Cerebral edema has been associated with high morbidity, high mortality, and high disability [1-4]. Pathologically, cerebral edema can be divided into two subtypes: 
cytotoxic and vasogenic cerebral edema. In the early stage of cerebral edema, it is mainly cytotoxic edema characterized by intracellular accumulation of fluid and $\mathrm{Na}^{+}$resulting in cell swelling. Several hours after the onset of cerebral edema, intracranial changes gradually become dominated by vasogenic cerebral edema. At this stage, it is characterized by extracellular accumulation of fluid resulting from disruption of the blood-brain barrier (BBB) and extravasations of serum proteins [2]. It has been reported that effective monitoring methods and timely intervention can help improve the prognosis [5-7]. Effective cerebral edema monitoring is still necessary which will help medical staff to adjust the therapeutic schedule in time.

The current gold standard for the diagnosis of cerebral edema is mainly based on imaging methods, such as Computed Tomography (CT) and Magnetic Resonance Imaging (MRI) [8]. The cost of CT or MRI scan is relatively expensive and these devices require expert operators. Also, CT scans are based on radiation, so there is difficulty in performing repeat scans on children. On the other hand, most imaging equipment is usually located in the radiology department. Thus, patients need extra referral for imaging, which increases the difficulty and procedures of nursing, especially for severe cases. In addition, early diagnosis requires collection of patient's physiological information as soon as possible. However, it is difficult for patients to undergo CT or MRI examinations in the first place. Besides, the imaging equipment is large and fit, which means that the traditional imaging methods cannot carry out bedside monitoring. The most widely used bedside monitoring tool is Intracranial Pressure (ICP) monitoring [9]. According to different measurement needs, the ICP probe can be inserted into the subdural, cerebral ventricle, and parenchyma [10]. However, as an invasive method, ICP causes secondary injury to patients, which may adversely affect the prognosis. In addition, ICP itself has not been currently an internationally recognized indicator of bedside monitoring [11]. Recent research found that ICP monitoring could hardly improve the functional outcome of moderate TBI, although it may possibly reduce the in-hospital mortality [12]. Another research also found that there was no relationship between ICP monitoring and clinical outcome for patients with Glasgow Coma Scale (GCS) scores of 3-8 [9].

In view of this situation, non-invasive bedside diagnosis and monitoring methods have become an attractive research field in recent years [13, 14]. Transcranial Doppler (TCD) utilizes ultrasound to detect variations in cerebra blood flow velocity of specific intracranial blood vessels (such as the middle artery), through which it can assess the level of intracranial blood supply [15]. However, TCD highly depends on medical staff and requires professional training. Generally, it can only be done by an ultrasound technician. Near-infrared spectroscopy (NIR) can be used as a monitoring tool of cerebral and myocardial oxygenation [16]. However, the measurement depth of NIR is limited [17]. Electrical Impedance Tomography (EIT) method measures the dielectric properties of biological tissues. Amid that different biological tissues have different electrical conductivity and permittivity at specific frequencies, lesions such as stroke or TBI which causes changes in intracranial components lead to changes in brain's dielectric parameters. However, EIT requires multiple electrodes attached to the scalp. The contact impedance brings inevitable interference to the measurement results [18]. Also, the skull, as a high resistance layer, will block the passage of current, which weakens the EIT signal [19]. The electromagnetic induction detection method is also based on the dielectric properties 
of biological tissues [20]. The advantage of this method is that the skull does not act as a barrier for the passage of electromagnetic waves [21]. This method uses electromagnetic waves to pass through the brain. Under certain pathological conditions (such as cerebral hemorrhage, cerebral ischemia, cerebral edema, etc.), the change of brain's dielectric properties can be measured via the signal from the receiving antenna [22]. Electromagnetic induction detection has developed many research branches. For example, Capacitively Coupled Electrical Impedance Tomography (CCEIT) uses low-frequency electric field to study the permittivity of biological tissues [19, 23]. However, the capacitive sensor used in the CCEIT method has low sensitivity in the deep part of the brain. There are also studies focusing on microwave-based detection, including microwave-based diagnosis $[24,25]$ and microwave imaging that use multiple antennas for discrimination [2629]. In addition, there are studies utilizing low-frequency magnetic induction method to measure vital signs [30-33], intracranial lesions [34-36], cancer [37-39], osteoporosis [40], suit fit [41], etc.

Electromagnetic induction has high potential application prospects in the field of diagnosis and monitoring of specific brain diseases. Oziel et al. utilized the Z-parameter to monitor the accumulation of blood in the head [42]. Teichmann et al. proposed a non-contact magnetic induction monitoring device that can measure pulse and respiratory activity via variation in the resonance frequency of the oscillatory circuitry [43-46]. Griffith developed a skin patch sensor and measure intracranial fluid-volume change via S-parameters from $700 \mathrm{MHz}$ to $1.1 \mathrm{GHz}$ [20]. Jiang et al. used an open-ended cylindrical waveguide for continuous assessment of intracerebral hemorrhage utilizing the $S_{11}$ parameter in a range of $100-400 \mathrm{MHz}$ [29]. Saied et al. designed an antenna system that propagates at $800 \mathrm{MHz}$ and $2.1 \mathrm{GHz}$, respectively for neurodegeneration monitoring. The resonant nature of the sensor, which can be assessed by $S_{11}$, can be used to differentiate between detecting brain atrophy and lateral ventricle enlargement [47]. However, there still are some unsolved issues in existing studies. Previous measurement methods, which only relies on the change trend of the phase shift of a single frequency or the frequency shift of the characteristic frequency, has been proved that it cannot be directly applied to detection and monitoring due to the complexity of the physiological structure and regulation mechanism of brain. There were studies showing that brain cannot be simply equivalent to a multilayer dielectric structure [42, 48, 49]. Pathological changes inside the brain cause one or more variations including intracranial volume, conductivity, permittivity, and the relative proportions of intracranial tissues. It is difficult to make diagnosis only based on the phase shift or frequency shift data. More importantly, this change is not linear. Our recent animal research based on the epidural freezing edema model has found that the electromagnetic induction signal and ICP showed fast change in the first $6 \mathrm{~h}$ on account of the strong intracranial compensatory effect. The change rate gradually decreased from 6 to 24th $\mathrm{h}$ with the exhaustion of compensatory [50]. According to the change trend of ICP and electromagnetic induction signals, it can be considered that in this rabbit edema model, the first $6 \mathrm{~h}$ is the acute phase of cerebral edema and the latter $6-24 \mathrm{~h}$ is the chronic phase. If the magnetic induction signals can provide hints at these two different stages of cerebral edema, this method may become a new indicator for early intervention. On the other hand, the latest research by Oziel et al. also showed that the amplitude/phase change has an increase or decrease 
or even a non-linear trend with the injected blood volume at different measurement frequencies [51-54]. At present, some studies have begun to use multi-frequency data combined with specific algorithms. Gen Li used multi-frequency reflection and transmission characteristics, combined with BP algorithm, to carry out brain edema monitoring [55]. Oziel also presented a single coil inductive device and the attendant algorithm for detection of changes in fluid/tissue ratio [52]. These studies were all targeted to use algorithms for $S$-parameter characteristic extraction and further analysis. Consequently, using proper algorithms to extract multiple parameters and multi-dimensional information can improve detection capabilities. Based on the above studies, this article proposes a hypothesis that the electromagnetic induction-based detection and distinction of acute/chronic phase of cerebral edema can be realized through a specialized characteristic parameter extraction algorithm.

In this study, an Amplitude-based Characteristic Parameter Extraction (Ab-CPE) algorithm was proposed based on the principle of multi-frequency electromagnetic induction and two-port network theory. For characteristic analysis, a 24-h monitoring experiment was carried out utilizing the rabbit liquid nitrogen freezing brain edema model. In particular, the performance of brain edema detection and the distinction of acute/chronic phase was investigated. This research is expected to provide algorithmic foundation for the clinical application of electromagnetic induction methods and bedside monitoring of cerebral edema.

\section{Results}

\section{Results of $S_{21}$ amplitude-frequency curve}

For illustration, Fig. 1 shows the amplitude-frequency data of rabbit Exp.6 in the experimental group at $4 \mathrm{~h}$ interval. It can be seen from Fig. 1a that when rabbit's brain is placed in the two-port network, its dielectric properties will affect the transmission parameters, resulting in various amplitude of $S_{21}$ at each frequency in $1-100 \mathrm{MHz}$, which is consistent with previous findings [20,52]. The dashed line in Fig. 1a showed its characteristic frequency. For further observation, Fig. 1b draws the amplitude-frequency curve within 52-62 MHz. It can be found that there are multiple variation characteristics in
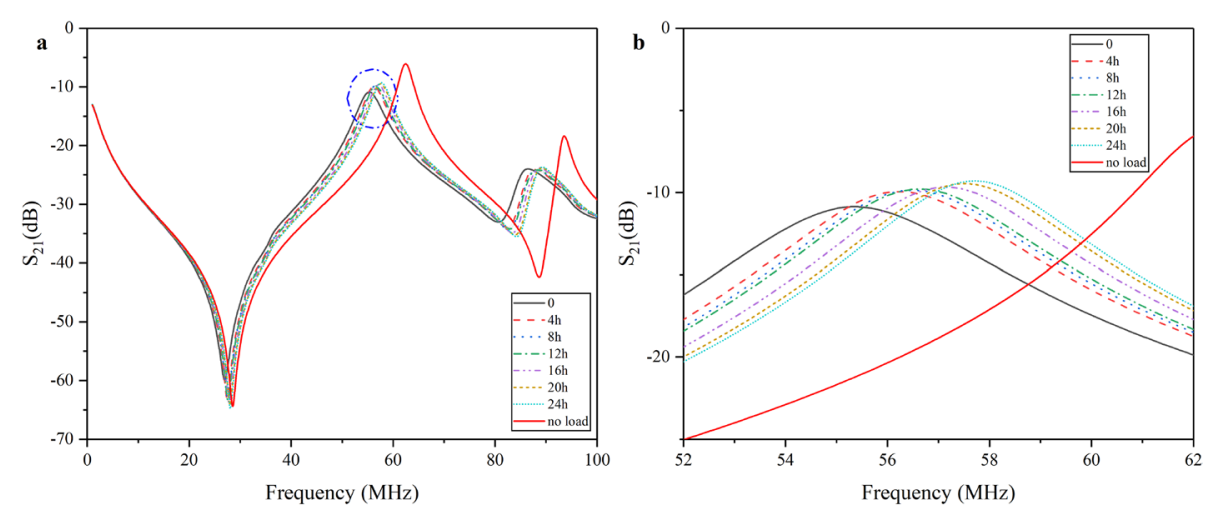

Fig. 1 Amplitude-frequency curve of rabbit Exp.6 in $24 \mathrm{~h}$. a Measurement data in 1-100 MHz. b Measurement data near characteristic frequency $(52-62 \mathrm{MHz})$ 
this curve. First, the peak value gradually increases and the characteristic frequency also shows a frequency shift trend.

Next, two frequency points near the characteristic frequency in the amplitudefrequency curve were selected to observe the change trend of the amplitude over time $(54.10 \mathrm{MHz}, 57.56 \mathrm{MHz})$. Results are shown in Fig. 2a. It can be seen that $S_{21}$ at $54.1 \mathrm{MHz}$ showed a downward trend. The decline rate was relatively linear within $0-15 \mathrm{~h}$ and gradually changed faster in 15-18 h. And finally, it tended to be stable again. At $57.56 \mathrm{MHz}, S_{21}$ showed an upward trend, in which it changed fast within $3 \mathrm{~h}$, and gradually slowed down in subsequent hours. Although change rate also increased during the $15-18 \mathrm{~h}$ period, the trend was not as obvious as that at $54.1 \mathrm{MHz}$. Figure $2 \mathrm{~b}$ plots the frequency shift trend of the characteristic frequency. It can be found that the characteristic frequency gradually increased. This trend was relatively obvious in the first $6 \mathrm{~h}$ and progressively stabilized in 6-15 h. Then, it started increasing again in 15-24 h. It can be concluded that $S_{21}$ contains rich variation characteristics near the characteristic frequency. Observing only the frequency shift or the amplitude change of $S_{21}$ at one frequency will miss part of the data trends [53].

\section{Detection of cerebral edema}

Figure 3 shows the characteristic parameters in experimental group and control group obtained by the Ab-CPE algorithm. All the five characteristic parameters of the experimental group had clear changes. In contrast, the characteristic parameters of control group had little change, especially for $\delta$ and $\rho$.

Table 1 lists the Receiver-Operating Characteristic (ROC) data of experimental group vs control group based on every possible combination of characteristic parameters. ROC is evaluated by Area Under Curve (AUC), where AUC $\in[0,1]$ and higher AUC represents better detection capability. The AUC of single characteristic parameters are relatively poor, of which all were lower than 0.9. Among those multi-parameter combinations, AUC of $\gamma \delta \rho$ was highest, reaching 0.9699.AUC of $\gamma \delta$ and $\gamma \rho$ is close to $\gamma \delta \rho$, reaching 0.9657 and 0.9658 , respectively. Thus, $\gamma \delta \rho$ can be selected as the detection characteristic parameters of cerebral edema.
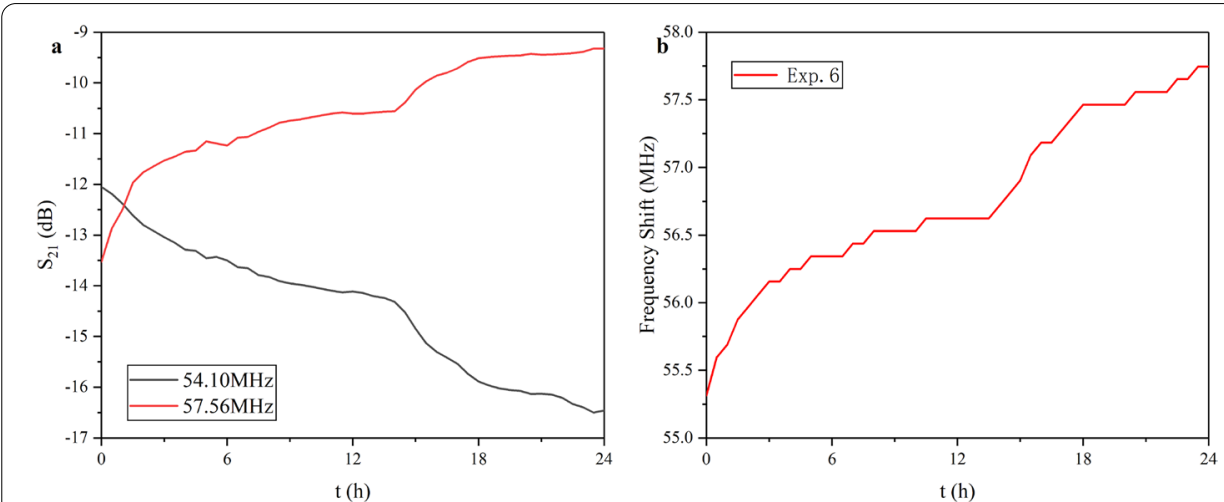

Fig. 2 a Change trend of the $S_{21}$ in $54.1 \mathrm{MHz}$ and $57.56 \mathrm{MHz}$ as a function of time. $\mathbf{b}$ Frequency shift trend of characteristic frequency as a function of time 


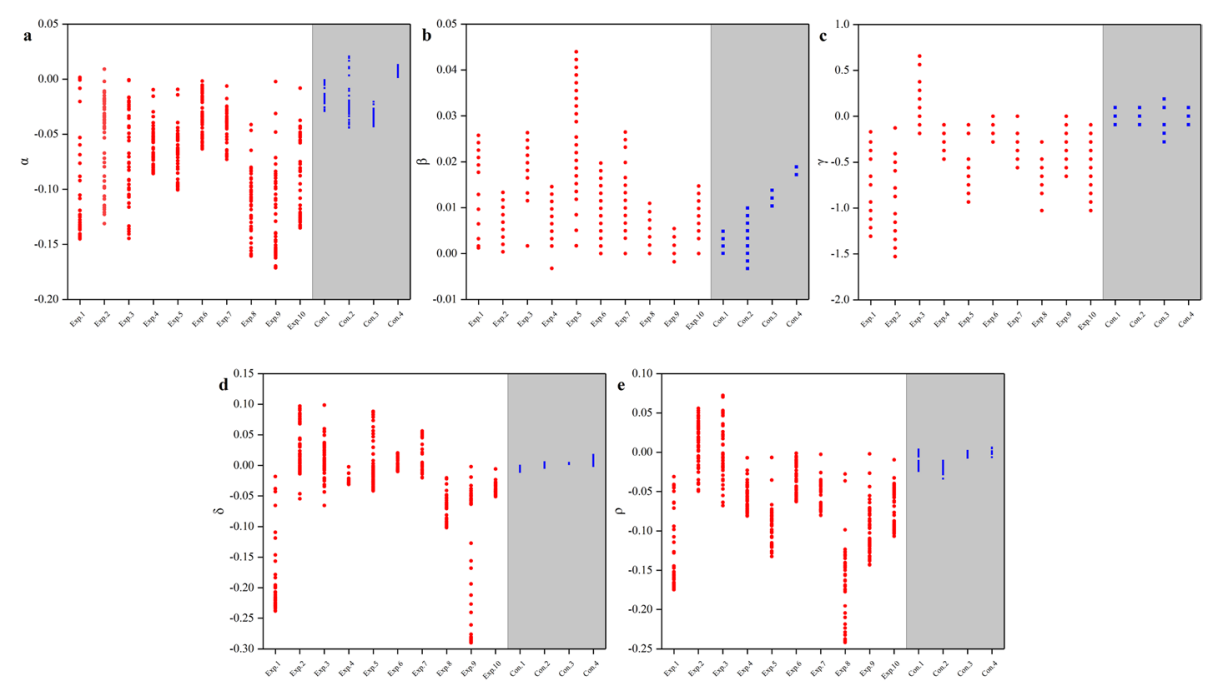

Fig. 3 Characteristic parameters in experimental group and control group. Ten rabbits (Exp.1-Exp.10) in experimental group were listed with white background. Four rabbits (Con.1-Con.4) in control group were listed with gray background

Table 1 ROC results of cerebral edema detection in $24 \mathrm{~h}$ based on every possible combination of characteristic parameters

\begin{tabular}{|c|c|c|c|c|c|c|c|c|c|}
\hline \multicolumn{2}{|l|}{ Single } & \multicolumn{2}{|l|}{ Double } & \multicolumn{2}{|l|}{ Triple } & \multicolumn{2}{|l|}{ Quadruple } & \multicolumn{2}{|l|}{ Quintuple } \\
\hline $\begin{array}{l}\text { Characteristic } \\
\text { parameter }\end{array}$ & $A \cup C^{*}$ & $\begin{array}{l}\text { Characteristic } \\
\text { parameter }\end{array}$ & AUC & $\begin{array}{l}\text { Characteristic } \\
\text { parameter }\end{array}$ & AUC & $\begin{array}{l}\text { Characteristic } \\
\text { parameter }\end{array}$ & AUC & $\begin{array}{l}\text { Characteristic } \\
\text { parameter }\end{array}$ & AUC \\
\hline$\alpha$ & 0.89 & $\alpha \beta$ & 0.84 & $\alpha \beta \gamma$ & 0.90 & $\alpha \beta \gamma \delta$ & 0.89 & $\alpha \beta \gamma \delta \rho$ & 0.92 \\
\hline$\beta$ & 0.72 & $\alpha \gamma$ & 0.92 & $\alpha \beta \delta$ & 0.87 & $\alpha \beta \gamma \rho$ & 0.95 & & \\
\hline$\gamma$ & 0.87 & $\alpha \delta$ & 0.90 & $\alpha \beta \rho$ & 0.87 & $\alpha \beta \delta \rho$ & 0.88 & & \\
\hline$\delta$ & 0.64 & $\alpha \rho$ & 0.90 & $\alpha \gamma \delta$ & 0.94 & $\alpha \gamma \delta \rho$ & 0.92 & & \\
\hline \multirow[t]{6}{*}{$\rho$} & 0.74 & $\beta \gamma$ & 0.84 & $\alpha \gamma \rho$ & 0.95 & $\beta \gamma \delta \rho$ & 0.91 & & \\
\hline & & $\beta \delta$ & 0.75 & $\alpha \delta \rho$ & 0.91 & & & & \\
\hline & & $\beta \rho$ & 0.77 & $\beta \gamma \delta$ & 0.88 & & & & \\
\hline & & $\gamma \delta$ & 0.97 & $\beta \gamma \rho$ & 0.89 & & & & \\
\hline & & $\gamma \rho$ & 0.97 & $\beta \delta \rho$ & 0.78 & & & & \\
\hline & & $\delta \rho$ & 0.94 & $\gamma \delta \rho$ & 0.97 & & & & \\
\hline
\end{tabular}

${ }^{*}$ AUC takes two significant digits

Figure $4 \mathrm{a}, \mathrm{b}$ plots the ROC curves based on single characteristic parameter and combination $\gamma \delta \rho$. The selected $\gamma \delta \rho$ parameters can achieve high sensitivity and specificity, reaching $94.1 \%$ and $95.4 \%$, respectively.

At the same time, we also selected the data within $1 \mathrm{~h}$ to evaluate the performance of Ab-CPE algorithm in early detection of cerebral edema. Results are shown in Table 2 . Consequently, the ROC result in early stage was slightly inferior to that in the whole $24 \mathrm{~h}$, but the highest AUC, the combination of $\gamma \delta \rho$, still reached 0.88 , which consisted with the results in Table 1.

Figure 5a, b plots the ROC curve within the first hour of experimental group vs control group. The optimal discrimination index based on $\gamma \delta \rho$ reached $85.0 \%$ sensitivity 

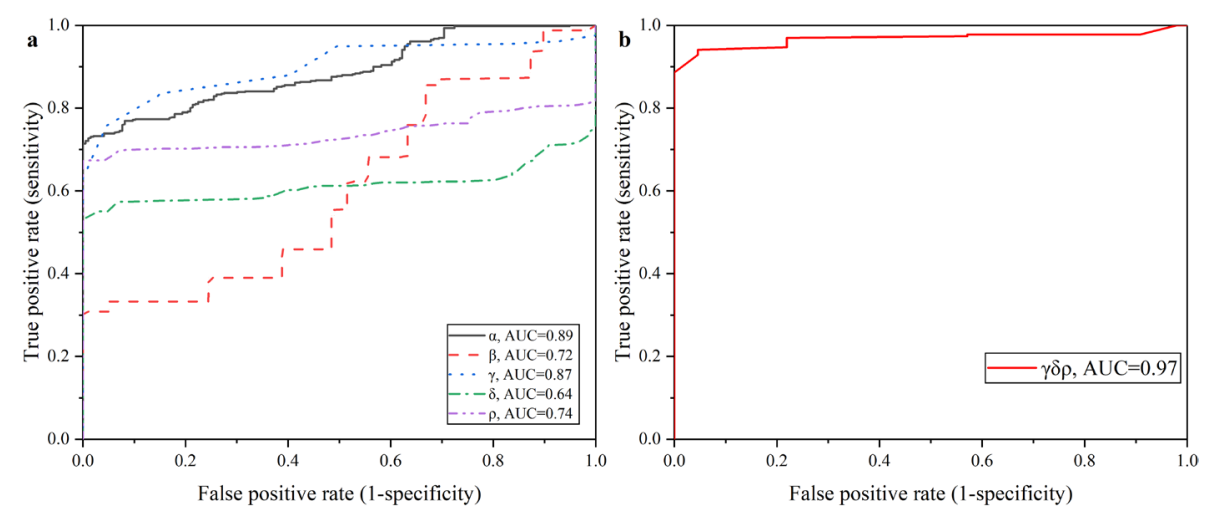

Fig. 4 ROC curve of experimental group vs control group distinction within $24 \mathrm{~h}$. a ROC curves based on single characteristic parameter; $\mathbf{b}$ ROC curves based on $\gamma \delta \rho$

Table 2 ROC results of cerebral edema detection in $1 \mathrm{~h}$ based on every possible combination of characteristic parameters

\begin{tabular}{|c|c|c|c|c|c|c|c|c|c|}
\hline \multicolumn{2}{|l|}{ Single } & \multicolumn{2}{|l|}{ Double } & \multicolumn{2}{|l|}{ Triple } & \multicolumn{2}{|l|}{ Quadruple } & \multicolumn{2}{|l|}{ Quintuple } \\
\hline $\begin{array}{l}\text { Characteristic } \\
\text { parameter }\end{array}$ & $A \cup C^{*}$ & $\begin{array}{l}\text { Characteristic } \\
\text { parameter }\end{array}$ & AUC & $\begin{array}{l}\text { Characteristic } \\
\text { parameter }\end{array}$ & AUC & $\begin{array}{l}\text { Characteristic } \\
\text { parameter }\end{array}$ & AUC & $\begin{array}{l}\text { Characteristic } \\
\text { parameter }\end{array}$ & AUC \\
\hline$\alpha$ & 0.77 & $\alpha \beta$ & 0.45 & $\alpha \beta \gamma$ & 0.55 & $\alpha \beta \gamma \delta$ & 0.64 & $\alpha \beta \gamma \delta \rho$ & 0.67 \\
\hline$\beta$ & 0.71 & $\alpha \gamma$ & 0.71 & $\alpha \beta \delta$ & 0.51 & $\alpha \beta \gamma \rho$ & 0.84 & & \\
\hline$\gamma$ & 0.72 & $\alpha \delta$ & 0.62 & $\alpha \beta \rho$ & 0.53 & $\alpha \beta \delta \rho$ & 0.59 & & \\
\hline$\delta$ & 0.59 & $\alpha \rho$ & 0.69 & $\alpha \gamma \delta$ & 0.74 & $\alpha \gamma \delta \rho$ & 0.62 & & \\
\hline \multirow[t]{6}{*}{$\rho$} & 0.73 & $\beta \gamma$ & 0.44 & $\alpha \gamma \rho$ & 0.83 & $\beta \gamma \delta \rho$ & 0.62 & & \\
\hline & & $\beta \delta$ & 0.61 & $\alpha \delta \rho$ & 0.71 & & & & \\
\hline & & $\beta \rho$ & 0.56 & $\beta \gamma \delta$ & 0.61 & & & & \\
\hline & & $\gamma \delta$ & 0.82 & $\beta \gamma \rho$ & 0.56 & & & & \\
\hline & & $\gamma \rho$ & 0.87 & $\beta \delta \rho$ & 0.65 & & & & \\
\hline & & $\delta \rho$ & 0.81 & $\gamma \delta \rho$ & 0.88 & & & & \\
\hline
\end{tabular}

AUC takes two significant digits
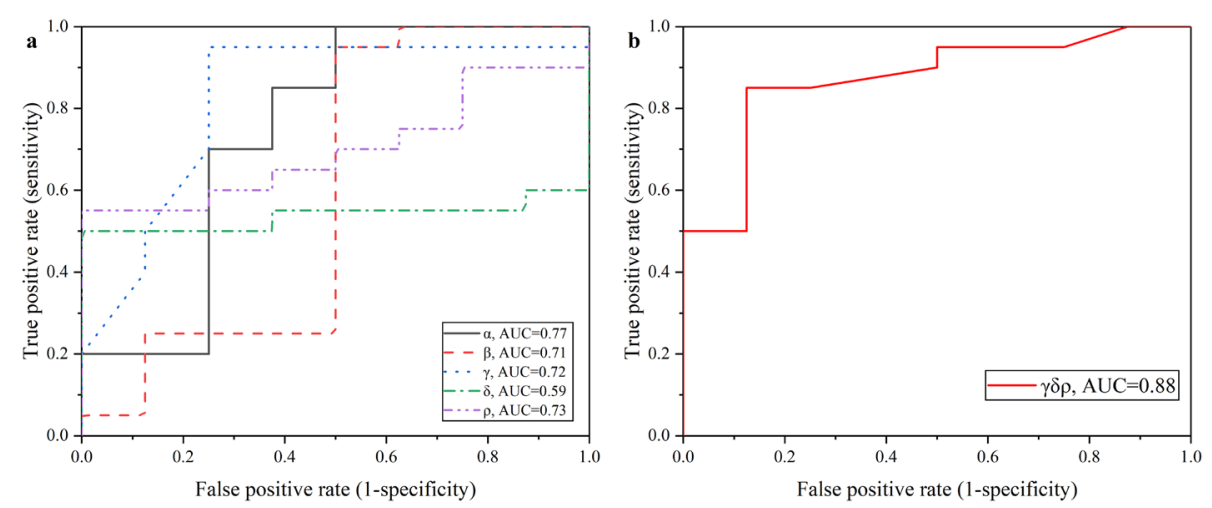

Fig. 5 ROC curve of experimental group vs control group distinction within $1 \mathrm{~h}$. a ROC curves based on single characteristic parameter; $\mathbf{b}$ ROC curves based on $\gamma \delta \rho$ 
and $87.5 \%$ specificity. The performance of Ab-CPE algorithm-based detection had indeed weakened in the early stage. There may be errors caused by insufficient data. There are not many data sampling points within $1 \mathrm{~h}$. In this experiment, data are sampled every $30 \mathrm{~min}$, so there are only two rounds of data within $1 \mathrm{~h}$ that can be enrolled for analysis. In the next step, the sampling rate will be increased in early stage. In all, the combination of $\gamma \delta \rho$ has the highest AUC both in $24 \mathrm{~h}$ and within $1 \mathrm{~h}$. It can be concluded that $\gamma \delta \rho$ is the optimal combination choice for the detection and early warning of cerebral edema.

\section{Distinction of acute/chronic phase of cerebral edema}

Aiming at the distinction between the acute and chronic phases of cerebral edema, this study also evaluated those characteristic parameters data within $0-6 \mathrm{~h}$ and $6-24 \mathrm{~h}$. We assumed that it is possible to distinguish between the acute and chronic phases of cerebral edema. Figure 6 plots the characteristic parameter of rabbits in the experimental group within 0-6 h and within 6-24 h, during which cytotoxicity and vasogenic cerebral edema, respectively, dominate the process in this cerebral edema model $[2,56]$. The contrast between the acute phase and the chronic phase of rabbits is not as clear as that between experimental group and control group. Among these characteristic parameters, the distribution in acute/chronic phase also overlaps partly.

Table 3 lists the ROC data of $0-6 \mathrm{~h}$ vs $6-24 \mathrm{~h}$ in experimental group based on every possible combination of characteristic parameters. It turns out that AUC of $\alpha \beta \gamma \delta \rho$ was highest, reaching 0.9326 .

Figure 7 plots the ROC curve of $0-6 \mathrm{~h}$ vs $6-24 \mathrm{~h}$ in experimental group. The AUC of single characteristic parameters were also relatively poor, of which all were lower than 0.85 . When combined all these five characteristic parameters, the optimal discrimination index can be achieved, reaching $85.0 \%$ sensitivity and $91.0 \%$ specificity.

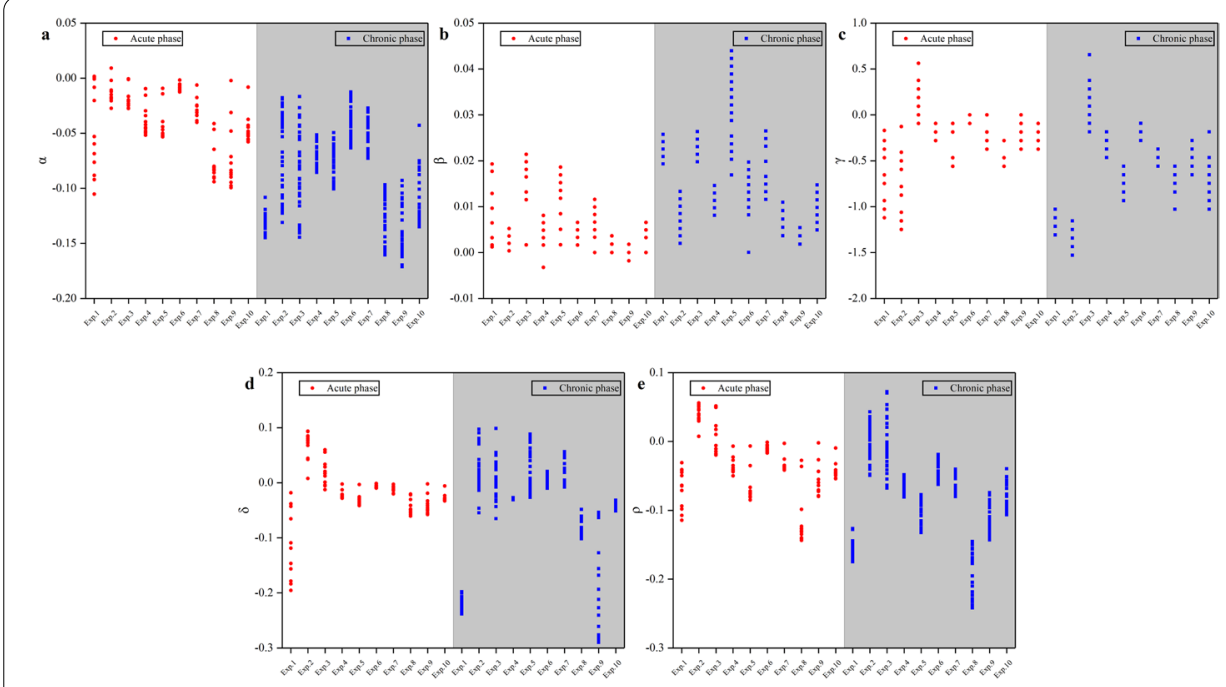

Fig. 6 Characteristic parameters of cerebral edema rabbits within $0-6 \mathrm{~h}$ and within $6-24 \mathrm{~h}$. Ten rabbits (Exp.1-Exp.10) in acute phase were listed with white background. Ten rabbits (Exp.1-Exp.10) in chronic phase were listed with gray background 
Table 3 ROC results of 0-6 h vs 6-24 h distinction in experimental group based on every possible combination of characteristic parameters

\begin{tabular}{|c|c|c|c|c|c|c|c|c|c|}
\hline \multicolumn{2}{|l|}{ Single } & \multicolumn{2}{|l|}{ Double } & \multicolumn{2}{|l|}{ Triple } & \multicolumn{2}{|l|}{ Quadruple } & \multicolumn{2}{|l|}{ Quintuple } \\
\hline $\begin{array}{l}\text { Characteristic } \\
\text { parameter }\end{array}$ & AUC $^{*}$ & $\begin{array}{l}\text { Characteristic } \\
\text { parameter }\end{array}$ & AUC & $\begin{array}{l}\text { Characteristic } \\
\text { parameter }\end{array}$ & AUC & $\begin{array}{l}\text { Characteristic } \\
\text { parameter }\end{array}$ & AUC & $\begin{array}{l}\text { Characteristic } \\
\text { parameter }\end{array}$ & AUC \\
\hline$\alpha$ & 0.83 & $\alpha \beta$ & 0.88 & $\alpha \beta \gamma$ & 0.88 & $\alpha \beta \gamma \delta$ & 0.87 & $\alpha \beta \gamma \delta \rho$ & 0.93 \\
\hline$\beta$ & 0.83 & $\alpha \gamma$ & 0.81 & $\alpha \beta \delta$ & 0.90 & $\alpha \beta \gamma \rho$ & 0.91 & & \\
\hline$\gamma$ & 0.65 & $\alpha \delta$ & 0.88 & $\alpha \beta \rho$ & 0.91 & $\alpha \beta \delta \rho$ & 0.90 & & \\
\hline$\delta$ & 0.64 & $\alpha \rho$ & 0.88 & $\alpha \gamma \delta$ & 0.89 & $\alpha \gamma \delta \rho$ & 0.93 & & \\
\hline \multirow[t]{6}{*}{$\rho$} & 0.69 & $\beta \gamma$ & 0.83 & $\alpha \gamma \rho$ & 0.88 & $\beta \gamma \delta \rho$ & 0.91 & & \\
\hline & & $\beta \delta$ & 0.85 & $\alpha \delta \rho$ & 0.88 & & & & \\
\hline & & $\beta \rho$ & 0.88 & $\beta \gamma \delta$ & 0.84 & & & & \\
\hline & & $\gamma \delta$ & 0.83 & $\beta \gamma \rho$ & 0.86 & & & & \\
\hline & & $\gamma \rho$ & 0.84 & $\beta \delta \rho$ & 0.88 & & & & \\
\hline & & $\delta \rho$ & 0.89 & $\gamma \delta \rho$ & 0.88 & & & & \\
\hline
\end{tabular}

*AUC takes two significant digits
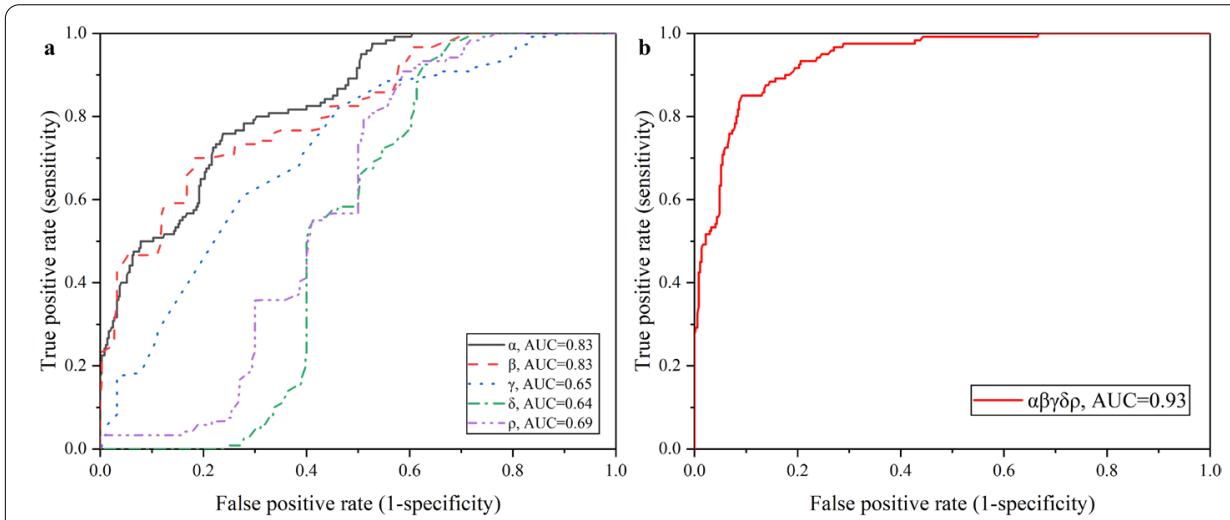

Fig. 7 ROC curve of experimental group vs control group distinction within 1 h. a ROC curves based on single characteristic parameter; $\mathbf{b}$ ROC curves based on $\gamma \delta \rho$

\section{Discussion}

As a high-incidence non-specific pathological swelling, cerebral edema seriously affects the prognosis. Especially for those hospitalized patients suffering from stroke, monitoring is urgently required. Electromagnetic induction measurement has high application prospects in bedside and point-of-care monitoring. Recently, Alruwailli et al. showed that resonant skin patch sensors can be used to detect changes in the cardiac intraventricular stroke volume, thereby providing a non-invasive monitoring index for stroke patients [57]. Mohammed et al. proposed a wearable readout system to carry out hemodynamic detection by extracting the radio frequency attributes of resonant frequency shift and magnitude variation [58,59]. This study demonstrates that, combined with our specific algorithms, the detection and distinction of acute/chronic cerebral edema can be realized in a non-invasive and bedside manner. The next iteration of development will be integration of hardware and algorithms into a wearable system to carry out clinical trials, through which may improve the prognosis. 
This study focuses on the amplitude-frequency data within the $3 \mathrm{~dB}$ bandwidth near the characteristic frequency. Hui et al. pointed out that, for the electromagnetic detection signals, the amplitude data have high stability and poor sensitivity. In contrast, the phase data have high sensitivity and poor stability. The phase data are more vulnerable to the change in relative position of the measured object [60]. Therefore, we chose the amplitude data and managed to improve the sensitivity through reasonable processing and analysis. In addition, many studies believed that the S-parameters data at this frequency point are correlated with intracranial changes [20,61, 62]. Studies by several teams such as Li, Pan, Oziel, and so on have focused on the data features near the characteristic frequency $[42,50,55,61,63]$. At this frequency, the two-port network indeed reached best impedance matching. Also, the radiation field radiated by the sensor has the strongest energy at this frequency. When the energy of this field reached largest, the weak disturbance of pathophysiological changes in biological tissues can modulate the near-electromagnetic field received by port 2 to the greatest extent, resulting in the maximum change of S-parameters in the frequency band.

Furthermore, five characteristic parameters were proposed in this study. Brain's equivalent impedance $Z=R+j \omega X$ will change due to intracranial lesions. This disturbance caused by intracranial lesions will have a complex impact on the electrical parameters of this two-port network, which may change the sensor's self-inductance $L$, parasitic capacitance $C$, and parasitic resistance $R$. The shift of the characteristic frequency to higher frequency does not necessarily represent the decrease of $C$. It may also be caused by the change of $L$. Similarly, the improvement in gain may not only be related to the change of $R$. The Ab-CPE algorithm comprehensively considers the change characteristics of the amplitude-frequency data near the characteristic frequency and the coupling mechanism between brain and the two-port network. The frequency where meets the maximum coupling coefficient of the coil sensor and the coupling degree can be reflected by parameter $\alpha$ and $\beta$. The parameter $\gamma$ extracted by the $3 \mathrm{~dB}$ bandwidth combined the multi-frequency data to comprehensively reflect the change of $Z$. Then, the parameters $\delta$ and $\rho$ were a composite transform on the former parameters. The results showed that although the single parameter-based result is not optimal, the optimal combinations of those characteristic parameters in cerebral edema detection and phase discrimination both contained $\gamma, \delta$, and $\rho$. This showed that the availability of multi-frequency data is higher. Combining characteristic parameters at multiple frequencies can improve robustness and accurately reflect the difference between different intracranial conditions. This also explains the complexity of brain's equivalent impedance change.

During the analysis of cerebral edema detection, the variations in S-parameters data were basically caused by metabolic activities such as blood supply and oxygen supply in control group. Compared with the drastic changes caused by brain edema, all the characteristic parameters of the control group were near 0 . Among those parameter combinations for the detection of cerebral edema, $\gamma \delta \rho$ is the best. This is also due to the high discrimination of the experimental group and the control group. Triple combination was enough for distinction and more parameters' combination may even bring unnecessary information. Evidently, the AUC results of quadruple and quintuple combinations showed that they are also capable for the detection requirements, and we just select the optimal solution. 
During the analysis of acute/chronic phase distinction, the distinction performance rose with multiple parameters included, reaching the highest when all parameters were enrolled. This means that each parameter was slightly different in the acute and chronic phase. Incorporating multiple parameters can improve the distinction accuracy. The reason why the best characteristic parameter combination in the acute/chronic phase distinction and detection of cerebral edema was different may be caused by the algorithm procedures. In the $\mathrm{Ab}-\mathrm{CPE}$ algorithm, combination of multiple parameters needs to be mapped to $[-1,1]$ for Euclidean distance calculation. The true value ranges of those parameters under the experimental design of detection and distinction are different. Thus, the relationship between different parameters may change after mapping, which leads to divergence in optimal solutions. This revealed that, in the subsequent clinical experiments, the electromagnetic induction data should be collected in a massive manner, by which we can obtain multiple characteristic parameters through specific algorithms. After that, iterative analysis and trial of all parameter combinations can be conducted to determine the optimal solution. The Ab-CPE algorithm proposed in this study provided a feasible solution for the clinical data in future researches.

Certainly, this study also has some limitations. This study currently only analyzed the transmission parameter $S_{21}$ in the S-parameter data. The next step may be the comprehensive analysis of all characteristics of this two-port test system by integrating all $\mathrm{S}$-parameters. In addition, this study focused on the narrow frequency band near the low-frequency characteristic frequency. Considering that biotissues have different coupling mechanisms in low-, medium-, and high-frequency electromagnetic fields, it is also necessary to broaden the working frequency $[51,64]$. In the next stage, we will consider methods such as adding switch matrix to carry out broadband research.

\section{Conclusion}

The multi-frequency and multi-parameter electromagnetic induction measurement data have great potential in the detection and monitoring of cerebral edema. Aiming at improving the effectiveness of cerebral edema detection and monitoring, this research proposed an Amplitude-based Characteristic Parameter Extraction (Ab-CPE) algorithm for characteristic analysis. It has been demonstrated that multi-frequency measurement data, combined with proper algorithm, have advantages over the traditional measure design. Notably, it is worthwhile to extract multi-dimensional characteristic parameters based on both coupling mechanism and data features for evaluation, through which the suitable parameter combination can be selected to improve accuracy. This research laid the foundation for the next step of multi-parameter and multi-sensor array research.

\section{Methods and materials}

\section{Principle of electromagnetic induction detection}

The dielectric properties of biotissues are frequency-dependent. Gabriel et al. measured the dielectric properties of various tissues over a wide frequency band. This database is widely used in electromagnetic induction-based detection studies [65-67]. Figure 8 shows the conductivity and relative permittivity of several brain tissues in 1-100 MHz. It can be found that the dielectric properties of brain tissues are frequency-dependent. 

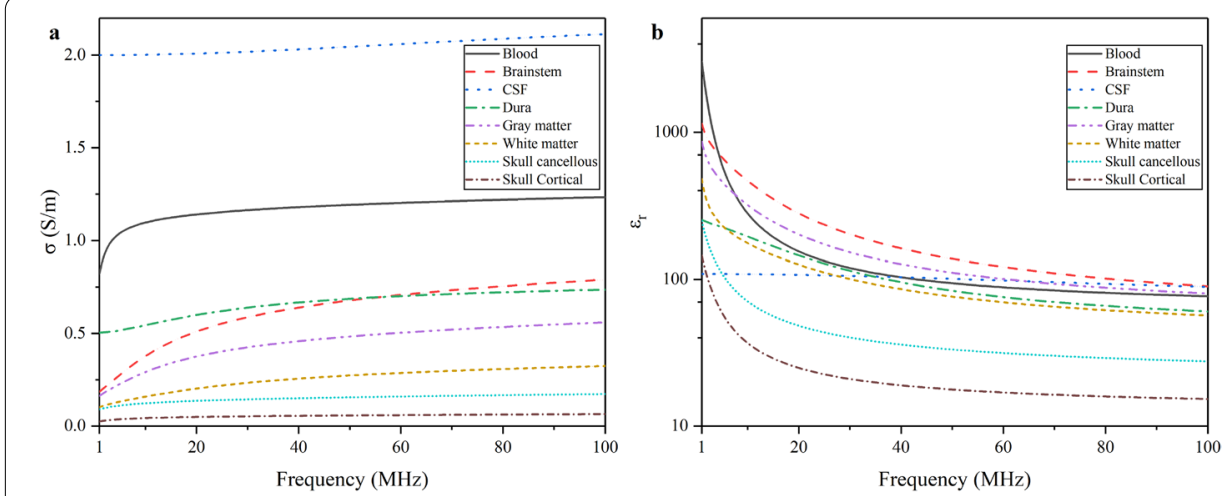

Fig. 8 Dielectric properties of brain tissues in $1-100 \mathrm{MHz}$. a Conductivity $\sigma$; $\mathbf{b}$ relative permittivity $\varepsilon_{r}$

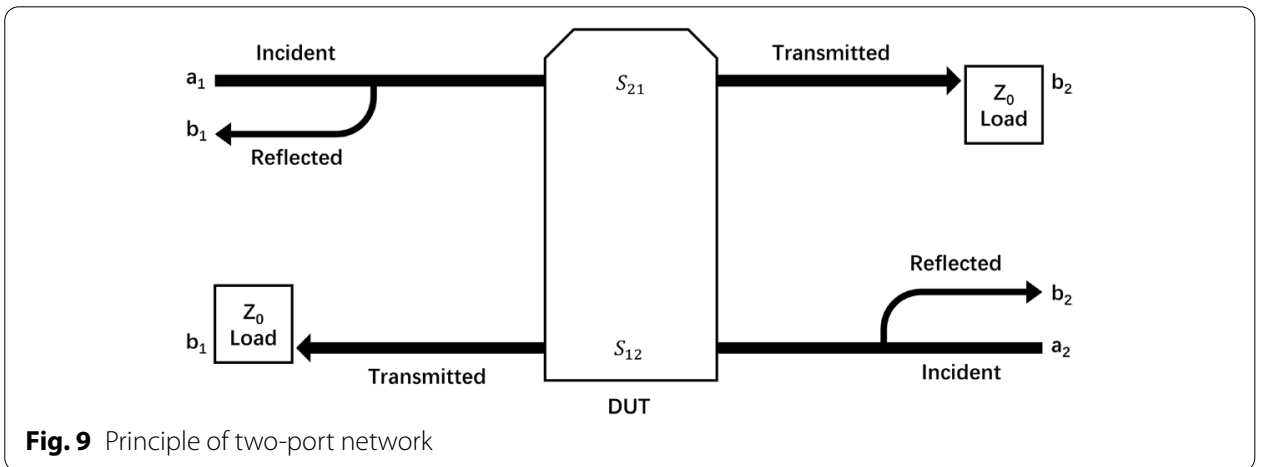

It can be found from Fig. 8 that the conductivity and permittivity of those brain tissues change with frequency, where different tissues have specific trend. For example, the $\sigma$ and $\varepsilon_{r}$ of the cerebrospinal fluid (CSF) do not significantly change in this frequency band and it has almost a linear relationship with frequency. By comparison, there is a non-linear relationship between blood's dielectric properties and frequency. Based on this fact, when intracranial components change relatively due to cerebral edema, the average conductivity and relative permittivity of the brain will change [68]. Furthermore, at different frequencies, the change trend of the whole intracranial dielectric parameters may be different.

According to the two-port network theory, bio tissue can be treated as the device under test (DUT). Figure 9 sketches out the principle of the two-port network system. At a specific frequency, the brain can be equivalent to a frequency-dependent complex impedance $Z_{L}=R+j \omega X$. This complex impedance $Z_{L}$ will show characteristic change when intracranial lesion occurs. Furthermore, this characteristic change can be extracted by measuring $S_{21}$ in scattering parameter (S-parameter) matrix

$$
\left[\begin{array}{l}
b_{1} \\
b_{2}
\end{array}\right]=\left[\begin{array}{ll}
S_{11} & S_{12} \\
S_{21} & S_{22}
\end{array}\right]\left[\begin{array}{l}
a_{1} \\
a_{2}
\end{array}\right]
$$


where $a_{1}, a_{2}$ are the incident wave and $b_{1}, b_{2}$ are the reflected wave of port 1 and port 2, respectively. Consequently, $S_{21}$ can be calculated by

$$
S_{21}=\frac{\text { transmitted }}{\text { incident }}=\left.\frac{b_{2}}{a_{1}}\right|_{a_{2}=0} .
$$

Studies have shown that because of the frequency dependence of the brain tissues' dielectric parameters, the S-parameters in the two-port network will show different amplitude within a given measurement frequency range. When $S_{21}$ has maximum value, the coupling coefficient is highest between brain and the two-port network. At this frequency, the electromagnetic wave which radiated from the port 1 penetrates the brain tissue and transmits to port 2 to the greatest extent [61-63, 69]. Using vector network analyzer (VNA) to carry out sweep measurements, the measurement data at different frequencies can be obtained for characteristic analysis.

\section{Measurement system and data collection}

Figure 10 shows the system diagram, the picture of the sensor, and its electromagnetic characteristics. The system consists of a RF vector network analyzer (Agilent E5061B, Keysight, USA), a homemade flexible conformal electromagnetic sensor which is desirable for local focusing measurement of CE [69], PC, and the Amplitude-based Characteristic Parameter Extraction algorithm. The VNA generates an excitation signal of a certain frequency, which is transmitted to the reference and port 1 through splitter. The excitation signal generates an electromagnetic field near the head via the sensor's excitation coil. The receiving coil collects the transmission signal and transmits it to
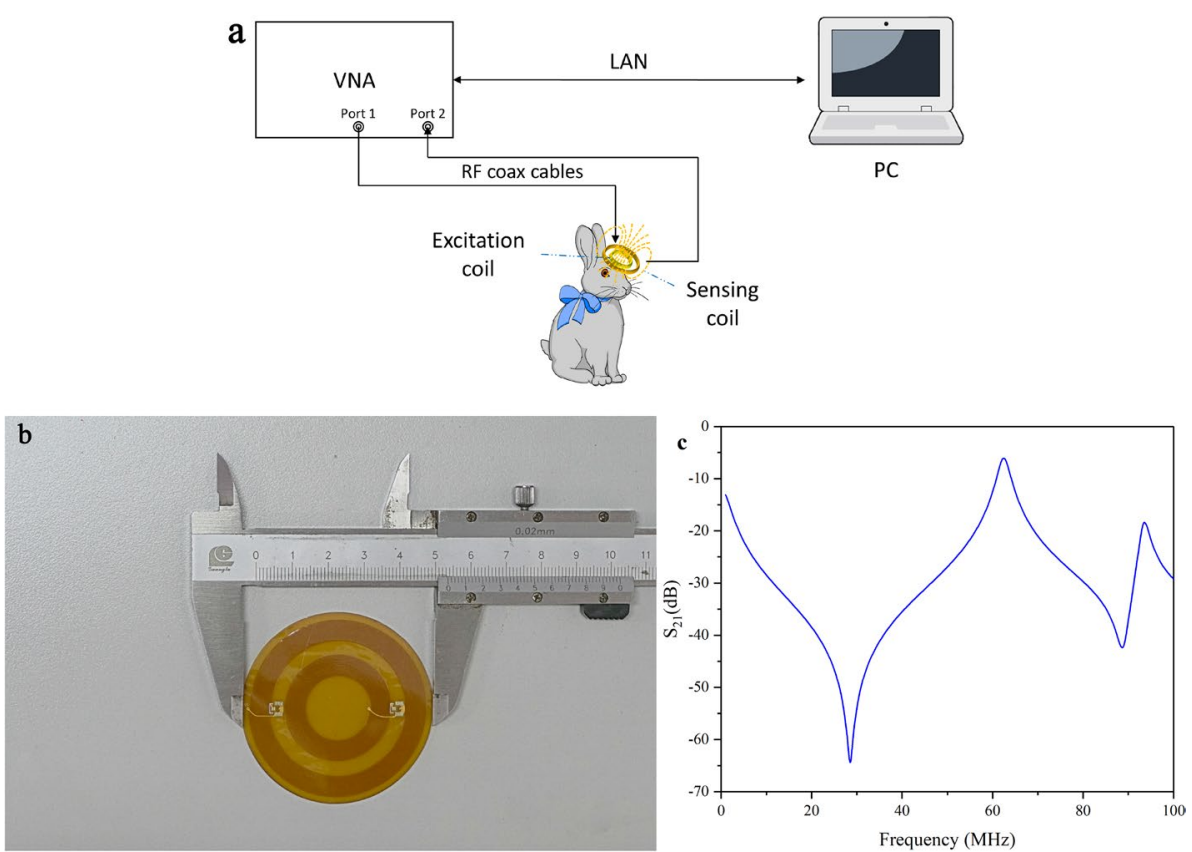

Fig. 10 a Diagram of electromagnetic induction detection system; b flexible conformal electromagnetic sensor; c amplitude-frequency curve of sensor without measured object 
port $2[61,63,69,70]$. The system parameters are set as follows. Sweep frequency range: 1-100 MHz; frequency points 1060; intermediate frequency (IF) bandwidth: $30 \mathrm{kHz}$; signal power: $10 \mathrm{dBm}$.

In this study, 14 rabbits (available from Daping Hospital, 2.0-3.0 kg) were enrolled in the animal experiments. Rabbits were arrived 1 day before experiments and housed under ambient conditions $\left(22{ }^{\circ} \mathrm{C}, 50 \%\right.$ relative humidity, and a 12-h light/dark cycle), with free access to water and chow. The rabbits were randomly divided into experimental group ( $n=10$, marked as Exp.1, Exp.2, .., Exp.10) and control group $(n=4$, marked as Con.1, Con.2, Con.3 and Con.4).

Our previous studies had proved the validity of the cerebral edema model established by epidural liquid nitrogen freezing method $[55,69,71]$. Thus, this model was still utilized in experimental group. Also, in contrast, rabbits in control group experienced the same procedure but without freezing. After the establishment of cerebral edema and control model, rabbits were fit on the board and monitored for $24 \mathrm{~h}$ while the flexible conformal electromagnetic sensor was placed close to the freezing point of the head. The sensor was fixed on rabbit's head by medical transparent adhesive tape to prevent body movement-induced relative displacement. This sensor can monitor local cerebral edema and has good bending robustness [69]. The measurement interval is set to once every $30 \mathrm{~min}$. Rabbits in both groups were euthanized via IV pentobarbital overdose at the end of monitoring. Experimental arrangement is shown in Fig. 11.

\section{Amplitude-based characteristic parameter extraction algorithm}

In this research, we proposed an Amplitude-based Characteristic Parameter Extraction (Ab-CPE) algorithm and input the measurement data for further characteristic analysis. Notably, this study selected the frequency points near characteristic frequency for further analysis. The Ab-CPE steps are as follows:

1) Define the measurement start time $t_{0}$ (the first measurement time). Record the amplitude-frequency curve of $S_{21}$ at $t_{0}$ and define $A_{0}\left(f_{0}\right)=\max \left(\left.S_{21}\right|_{t_{0}}\right) . f_{0}$ is the frequency where $A_{0}\left(f_{0}\right)$ is. Then, find the lower frequency $f_{0}^{\prime}$ and upper frequency $f_{0}^{\prime \prime}$ where $S_{21}\left(f_{0}^{\prime}\right)=S_{21}\left(f_{0}^{\prime \prime}\right)=A_{0}\left(f_{0}\right)-3, f_{0}^{\prime}<f_{0}<f_{0}^{\prime \prime}$. After, the $3 \mathrm{~dB}$ bandwidth (half-power bandwidths) $F_{0}$ at time $t_{0}$ is

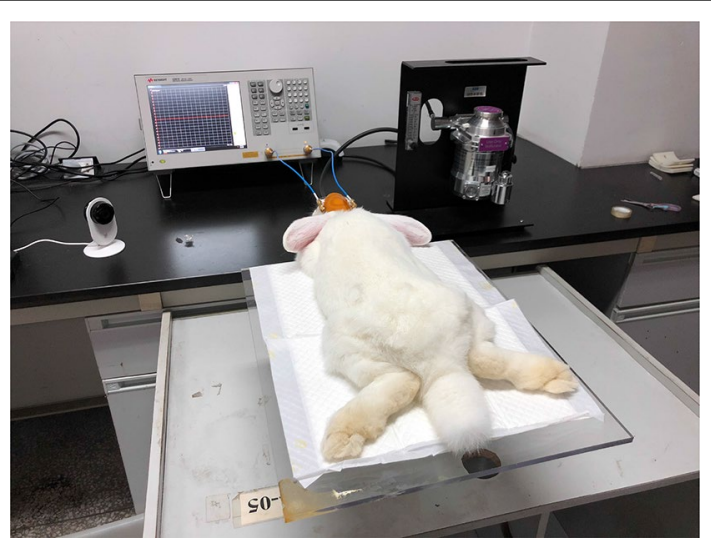

Fig. 11 24-h real-time monitoring experiments in rabbits 


$$
F_{0}=f_{0}^{\prime \prime}-f_{0}^{\prime}
$$

Denote $N_{0}$ as the number of frequency points contained in the $3 \mathrm{~dB}$ bandwidth. Furthermore, calculate the mean amplitude of all frequency points in $F_{0}$ at $t_{0}$

$$
\bar{a}_{0}=\sum_{n=1}^{N} S_{21}\left(f_{n}\right) / N .
$$

2) Define the subsequent $i$ th measurement as $t_{i}$. Record the amplitude-frequency curve of $S_{21}$ at $t_{i}$ and define $A_{i}\left(f_{i}\right)=\max \left(\left.S_{21}\right|_{t_{i}}\right) . f_{i}$ is the frequency where $A_{i}\left(f_{i}\right)$ is. Then, find the lower frequency $f_{i}^{\prime}$ and upper frequency $f_{i}^{\prime \prime}$ where $S_{21}\left(f_{i}^{\prime}\right)=S_{21}\left(f_{i}^{\prime \prime}\right)=$ $A_{i}\left(f_{i}\right)-3, f_{i}^{\prime}<f_{i}<f_{i}^{\prime \prime}$. After, the $3 \mathrm{~dB}$ bandwidth $F_{i}$ at time $t_{i}$ is

$$
F_{i}=f_{i}^{\prime}-f_{i}^{\prime \prime} .
$$

Denote $N_{i}$ as the number of frequency points contained in the $3 \mathrm{~dB}$ bandwidth. Define the mean amplitude of all frequency points in $F_{0}$ at $t_{i}$

$$
\bar{a}_{i}=\sum_{n=1}^{N} S_{21}\left(f_{n}\right) / N_{0}, f_{n} \in F_{0} .
$$

Define the $3 \mathrm{~dB}$ bandwidth followed mean amplitude of all frequency points in $F_{i}$ at $t_{i}$ :

$$
\overline{a_{i}^{\prime}}=\sum_{n=1}^{N} S_{21}\left(f_{n}\right) / N_{i}, f_{n} \in F_{i} .
$$

3) Define maximum characteristic parameter $\alpha$ :

$$
\alpha=\left[A_{i}\left(f_{i}\right)-A_{0}\left(f_{0}\right)\right] / A_{0}\left(f_{0}\right) .
$$

4) Define frequency shift characteristic parameter $\beta$ :

$$
\beta=\left(f_{i}-f_{0}\right) / f_{0} .
$$

5) Define $3 \mathrm{~dB}$ characteristic parameter $\gamma$ :

$$
\gamma=\left(F_{i}-F_{0}\right) / F_{0} .
$$

6) Define mean amplitude characteristic parameter $\delta$ :

$$
\delta=\left(\bar{a}_{i}-\bar{a}_{0}\right) / \bar{a}_{0} .
$$

7) Define followed mean amplitude characteristic parameter $\rho$ :

$$
\rho=\left(\overline{a_{i}^{\prime}}-\bar{a}_{0}\right) / \bar{a}_{0} .
$$




\section{Characteristic analysis based on the Ab-CPE algorithm}

Figure 12 shows the diagram of characteristic analysis based on the Ab-CPE algorithm. The data analysis in this study was conducted by MATLAB (MathWorks, Inc., USA), by which the Ab-CPE algorithm and ROC analysis was carried out.

We assumed that the characteristic parameters extracted from this Ab-CPE algorithm can be used to detect cerebral edema and distinguish the acute and chronic phase. For single characteristic parameter, threshold $T$ is set for binary classification. For the combination of multiple parameters, we use Euclidean distance to set the threshold $T$ and map these parameters to $[-1,1]$ to eliminate the influence of value difference between those characteristic parameters. Take parameter $\alpha$ and $\beta$ as an example

$$
\alpha_{i} \leq T \leq \alpha_{j}, i\{\text { Exp. }\}, j\{\text { Con. }\}
$$

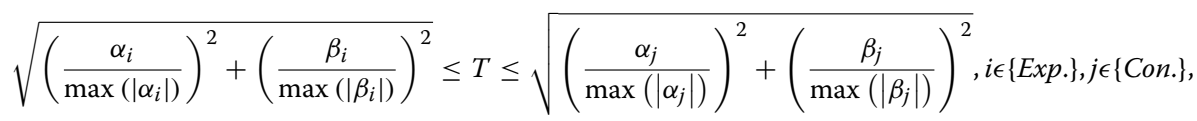

where $\{E x p$. $\}$ represents the $\alpha$ value of the experimental group within $24 \mathrm{~h}$, and \{Con.\} represents the $\alpha$ value of the control group within $24 \mathrm{~h}$. Here, we set $\operatorname{mean}(\{$ Con. $\}) \geq \operatorname{mean}(\{$ Exp. $\})$ for expression purpose. Using Eq. (13), (14) for every possible combination of characteristic parameters, the performance of cerebral edema detection can be evaluated. Furthermore, take only those data where $\{\operatorname{Exp} .\}^{\prime}=\{\operatorname{Exp} . \mid 0-1 h\}$ and $\{\text { Con. }\}^{\prime}=\{$ Con. $\mid 0-1 h\}$, we can evaluate the detection performance in early stage.

Similarly, different $T^{\prime}$ in Eqs. (15) and (16) can evaluate the capability of Ab-CPE in distinction between acute and chronic phase. Take parameter $\alpha$ and $\beta$ as an example

$$
\alpha_{i} \leq T^{\prime} \leq \alpha_{j}, i \epsilon\{\operatorname{Exp} . \mid 0-6 h\}, j \epsilon\{\operatorname{Exp} . \mid 6-24 h\}
$$

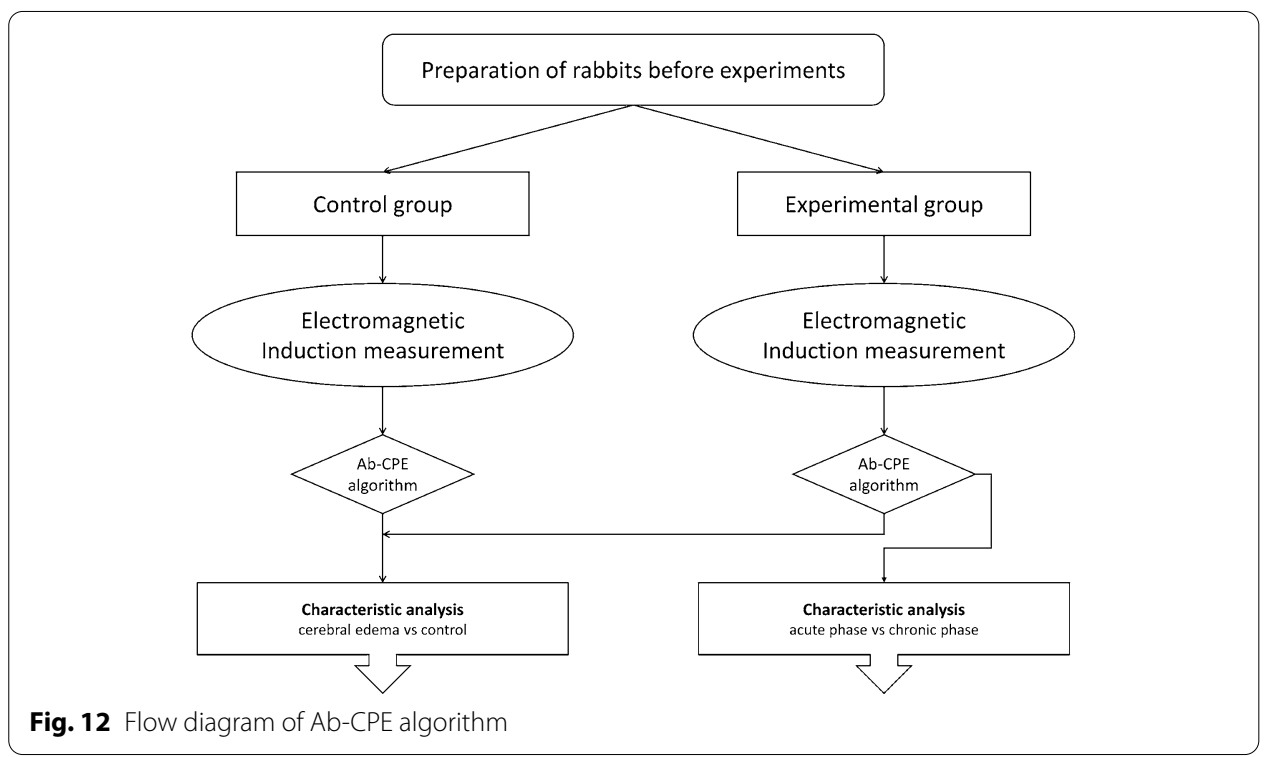




$$
\begin{aligned}
& \sqrt{\left(\frac{\alpha_{i}}{\max \left(\left|\alpha_{i}\right|\right)}\right)^{2}+\left(\frac{\beta_{i}}{\max \left(\left|\beta_{i}\right|\right)}\right)^{2}} \leq T^{\prime} \\
& \leq \sqrt{\left(\frac{\alpha_{j}}{\max \left(\left|\alpha_{j}\right|\right)}\right)^{2}+\left(\frac{\beta_{j}}{\max \left(\left|\beta_{j}\right|\right)}\right)^{2}}, i \epsilon\{\operatorname{Exp} . \mid 0-6 h\}, j \epsilon\{\operatorname{Exp} . \mid 6-24 h\} .
\end{aligned}
$$

\begin{abstract}
Abbreviations
Ab-CPE: Amplitude-based characteristic parameter extraction; TBI:Traumatic brain injury; BBB: Blood-brain barrier; CT: Computed tomography; MRI: Magnetic resonance imaging; ICP: Intracranial pressure; GCS: Glasgow Coma Scale; TCD: Transcranial Doppler sonography; NIR: Near-infrared spectroscopy; EIT: Electrical Impedance Tomography; CCETI: Capacitively Coupled Electrical Impedance Tomography; MIPS: Magnetic induction phase shift; S-parameter: Scattering parameter; VNA: Vector network analyzer; IF: Intermediate frequency; ROC: Receiver-operating characteristic; AUC: Area under curve.
\end{abstract}

\title{
Acknowledgements
}

Thank you to Electronic Engineering Teaching and Research Office for the support of this research. The authors are very grateful to the National Natural Science Foundation of China and the Natural Science Foundation of Chongqing. We are also very grateful to the Chongqing Technology Innovation and Application Demonstration Project.

\section{Authors' contributions}

$M X Q$ was responsible for the design and overall investigation. JBC and $H Y L$ were responsible for Ab-CPE algorithm. GL and JS were responsible for measurement system design. JBC, SLZ, and GL were responsible for experiment part. JBC, GL, and JS were responsible for data analysis and chart making. JBC was a major contributor in writing the manuscript. All authors read and approved the final manuscript.

\section{Funding}

This research was funded by the National Natural Science Foundation of China (grant number 51977214, 62001070), the Natural Science Foundation of Chongqing (No. cstc2020jcyj-msxmX0322), and Chongqing Technology Innovation and Application Demonstration Project (No. cstc2018jscx-msybX1094).

\section{Availability of data and materials}

All data generated or analyzed during this study are included in this published article.

\section{Declarations}

Ethics approval and consent to participate

These experiments were conducted under the guidance of the Administration of Animal Experiments for Medical Research Purpose issued by the Ministry of Health of China. The protocol was reviewed and approved by the Animal Experiments and Ethical Committee of Army Medical University (AMU, Chongqing, China). Animal care was performed in accordance with the Declaration of Helsinki and the guidelines issued by the International Association for the Study of Pain.

\section{Consent for publication}

Not applicable.

\section{Competing interests}

The authors declare that they have no competing interests.

\section{Author details}

${ }^{1}$ College of Biomedical Engineering, Third Military Medical University (Army Medical University), Chongqing, China.

${ }^{2}$ School of Pharmacy and Bioengineering, Chongqing University of Technology, Chongqing, China. ${ }^{3}$ China Aerodynamics Research and Development Center Low Speed Aerodynamic Institute, Mianyang, Sichuan, China.

Received: 7 January 2021 Accepted: 26 July 2021

Published online: 03 August 2021

\section{References}

1. Selim M, Norton C. Perihematomal edema: Implications for intracerebral hemorrhage research and therapeutic advances. J Neurosci Res. 2018;98(1):212-8.

2. Michinaga S, Koyama Y. Pathogenesis of brain edema and investigation into anti-edema drugs. Int J Mol Sci. 2015;16(5):9949-75.

3. Parry-Jones AR, Wang X, Sato S, Mould WA, Vail A, Anderson CS, Hanley DF. Edema extension distance: outcome measure for phase II clinical trials targeting edema after intracerebral hemorrhage. Stroke. 2015;46(6):e137-40. 
4. Cook AM, Morgan Jones G, Hawryluk GW, Mailloux P, McLaughlin D, Papangelou A, Samuel S, Tokumaru S, Venkatasubramanian C, Zacko C. Guidelines for the acute treatment of cerebral edema in neurocritical care patients. Neurocrit Care. 2020;32:1-20.

5. Ehntholt MS, Parasram M, Mir SA, Lerario MP. Mobile stroke units: bringing treatment to the patient. Curr Treat Option Ne. 2020;22(2):5.

6. Helwig SA, Ragoschke-Schumm A, Schwindling L, Kettner M, Roumia S, Kulikovski J, Keller I, Manitz M, Martens D, Grün D. Prehospital stroke management optimized by use of clinical scoring vs mobile stroke unit for triage of patients with stroke: a randomized clinical trial. Jama Neurol. 2019;76(12):1484-92.

7. Wu TY, Sharma G, Strbian D, Putaala J, Desmond PM, Tatlisumak T, Davis SM, Meretoja A. Natural history of perihematomal edema and impact on outcome after intracerebral hemorrhage. Stroke. 2017;48(4):873-9.

8. Tipirneni-Sajja A, Christensen S, Straka M, Inoue M, Lansberg MG, Mlynash M, Bammer R, Parsons MW, Donnan GA, Davis SM. Prediction of final infarct volume on subacute MRI by quantifying cerebral edema in ischemic stroke. J Cereb Blood Flow Metab. 2017;37(8):3077-84.

9. Ren J, Wu X, Huang J, Cao X, Yuan Q, Zhang D, Du Z, Zhong P, Hu J. Intracranial pressure monitoring-aided management associated with favorable outcomes in patients with hypertension-related spontaneous intracerebral hemorrhage. Transl Stroke Res. 2020;11(6):1253-63.

10. Ristic A, Sutter R, Steiner LA. Current neuromonitoring techniques in critical care. J Neuroanaesthesiol Crit Care. 2015;2(02):97-103.

11. Heldt T, Zoerle T, Teichmann D, Stocchetti N. Intracranial pressure and intracranial elastance monitoring in neurocritical care. Annu Rev Biomed Eng. 2019;21:523-49.

12. Li Z, Xu F, Li Y, Wang R, Zhang Z, Qu Y. Assessment of intracranial pressure monitoring in patients with moderate traumatic brain injury: a retrospective cohort study. Clin Neurol Neurosur. 2020;189:105538.

13. Hiles LA, Donoviel DB, Bershad EM. Noninvasive brain physiology monitoring for extreme environments: a critical review. J Neurosurg Anesth. 2015;27(4):318-28.

14. Brochard L, Martin GS, Blanch L, Pelosi P, Belda FJ, Jubran A, Gattinoni L, Mancebo J, Ranieri VM, Richard JM. Clinical review: respiratory monitoring in the ICU-a consensus of 16. Crit Care. 2012;16(2):219.

15. Rasulo FA, Bertuetti R, Robba C, Lusenti F, Cantoni A, Bernini M, Girardini A, Calza S, Piva S, Fagoni N. The accuracy of transcranial Doppler in excluding intracranial hypertension following acute brain injury: a multicenter prospective pilot study. Crit Care. 2017;21(1):44.

16. Yang $M$, Wang $P$, Yang Z, Yuan T, Feng W. A systemic review of functional near-infrared spectroscopy for stroke: current application and future directions. Front Neurol. 2019;10:58.

17. Strangman GE, Li Z, Zhang Q. Depth sensitivity and source-detector separations for near infrared spectroscopy based on the Colin27 brain template. PLoS ONE. 2013;8(8):e66319.

18. McDermott BJ, Ohalloran M, Avery J, Porter E. Bi-frequency symmetry difference EIT-feasibility and limitations of application to stroke diagnosis. IEEE J Biomed Health. 2019;24(8):2407-19.

19. Jiang YD, Soleimani M. Capacitively coupled electrical impedance tomography (CCEIT) for brain imaging. leee T Med Imaging. 2019;38(9):2104-13.

20. Griffith J, Cluff K, Eckerman B, Aldrich J, Becker R, Moore-Jansen P, Patterson J. Non-invasive electromagnetic skin patch sensor to measure intracranial fluid-volume shifts. Sensors. 2018;18(4):1022.

21. González CA, Rubinsky B. The detection of brain oedema with frequency-dependent phase shift electromagnetic induction. Physiol Meas. 2006;27(6):539-52.

22. Mehrotra P, Chatterjee B, Sen S. EM-Wave biosensors: a review of RF, microwave, mm-wave and optical sensing. Sensors. 2019;19(5):1013.

23. Jiang Y, Soleimani M. Capacitively coupled phase-based dielectric spectroscopy tomography. Sci Rep. 2018;8(1):17526.

24. Fhager A, Candefjord S, Elam M, Persson M. 3D simulations of intracerebral hemorrhage detection using broadband microwave technology. Sensors. 2019;19(16):3482.

25. Kellner CP, Sauvageau E, Snyder KV, Fargen KM, Arthur AS, Turner RD, Alexandrov AV. The VITAL study and overall pooled analysis with the VIPS non-invasive stroke detection device. J Neurointerv Surg. 2018;10(11):1079-84.

26. Wang P, Ma Y, Liang F, Zhang Y, Yu X, Li Z, An Q, Lv H, Wang J. Non-contact vital signs monitoring of dog and cat using a UWB radar. Animals. 2020;10(2):205.

27. Ringkamp J, Radler P, Lebhardt P, Langejürgen J. A novel non-invasive, non-conductive method for measuring respiration. J Sensors Sensor Syst. 2020;9(1):27-32.

28. Rahman MA, Hossain MF, Riheen MA, Sekhar PK. Early brain stroke detection using flexible monopole antenna. Progr Electromagn Res. 2020;99:99-110.

29. Yuhao J, Minji Z, Lu W, Li Y, Yang J. Microwave based detector for continuous assessment of intracerebral hemorrhage. Sci China Technol Sci. 2019;62(3):365-72.

30. Tarjan PP, McFee R. Electrodeless measurements of the effective resistivity of the human torso and head by magnetic induction. IEEET Bio-Med Eng. 1968;4:266-78.

31. Guardo R, Trudelle S, Adler A, Boulay C, Savard P: Contactless recording of cardiac related thoracic conductivity changes. In Proceedings of 17th International Conference of the Engineering in Medicine and Biology Society:1995. IEEE; 1995:1581-1582.

32. Zeng $\mathrm{X}$, Robakowski J, Persson M, Monteith A, Fhager A. Investigation of an ultra wideband noise sensor for health monitoring. Sensors. 2020;20(4):1034.

33. Hui X, Kan EC. No-touch measurements of vital signs in small conscious animals. Sci Adv. 2019;5(2):169.

34. Manoufali M, Mobashsher AT, Mohammed B, Bialkowski K, Mills PC, Abbosh A. Implantable sensor for detecting changes in the loss tangent of cerebrospinal fluid. IEEE T Biomed Circ S. 2020;14:1.

35. Xiao Z, Tan C, Dong F. 3-D hemorrhage imaging by cambered magnetic induction tomography. IEEE T Instrum Meas. 2019;68(7):2460-8. 
36. Zhao S, Jin G, Bai Z, Chen J, Li M, Li G, Zhuang W, Liu Y, Qin M. Twenty-four-hour real-time continuous monitoring of acute focal cerebral ischemia in rabbits based on magnetic inductive phase shift. Biomed Eng Online. 2020;19(1):1-15.

37. Aldhaeebi MA, Almoneef TS, Attia H, Ramahi OM. Electrically small magnetic probe with PCA for near-field microwave breast tumors detection. Progr Electromagn Res. 2019;84:177-86.

38. Aldhaeebi MA, Almoneef TS, Attia H, Ramahi OM. Near-field microwave loop array sensor for breast tumor detection. IEEE Sens J. 2019;19(24):11867-72.

39. Porter E, Bahrami H, Santorelli A, Gosselin B, Rusch LA, Popović M. A wearable microwave antenna array for timedomain breast tumor screening. IEEE T Med Imaging. 2016;35(6):1501-9.

40. Makarov SN, Noetscher GM, Arum S, Rabiner R, Nazarian A. Concept of a radiofrequency device for osteopenia/ osteoporosis screening. Sci Rep. 2020;10(1):1-15.

41. Loflin B, Cluff K, Griffith J, Mohammed N. Identification of shoulder joint clearance in space suit using electromagnetic resonant spiral proximity sensor for injury prevention. Acta Astronaut. 2020;170:46-54.

42. Oziel M, Korenstein R, Rubinsky B. Radar based technology for non-contact monitoring of accumulation of blood in the head: A numerical study. PLoS ONE. 2017;12(10):e186381.

43. Teichmann D, De Matteis D, Bartelt T, Walter M, Leonhardt S. A bendable and wearable cardiorespiratory monitoring device fusing two noncontact sensor principles. IEEE J Biomed Health. 2015;19(3):784-93.

44. Teichmann D, Kuhn A, Leonhardt S, Walter M. The MAIN Shirt: a textile-integrated magnetic induction sensor array. Sensors. 2014;14(1):1039-56.

45. Teichmann D, Kuhn A, Leonhardt S, Walter M. Human motion classification based on a textile integrated and wearable sensor array. Physiol Meas. 2013;34(9):963.

46. Teichmann D, Foussier J, Buscher M, Walter M, Leonhardt S. Textile integration of a magnetic induction sensor for monitoring of cardiorespiratory activity. Berlin: Springer; 2013.

47. Saied I, Chandran S, Arslan T. Integrated flexible hybrid silicone-textile dual-resonant sensors and switching circuit for wearable neurodegeneration monitoring systems. IEEE T Biomed Circ S. 2019;13(6):1304-12.

48. Goss D, Mackin RO, Crescenzo E, Tapp HS, Peyton AJ: Understanding the coupling mechanism in high frequency EMT. 2003.

49. Griffiths $H$, Gough W, Watson S, Williams RJ. Residual capacitive coupling and the measurement of permittivity in magnetic induction tomography. Physiol Meas. 2007;28(7):S301.

50. Zhao S, Li G, Gu S, Ren J, Chen J, Xu L, Chen M, Yang J, Leung K, Sun J. An experimental study of relationship between magnetic induction phase shift and brain parenchyma volume with brain edema in traumatic brain injury. IEEE Access. 2019;7:20974-83.

51. Oziel M, Korenstein R, Rubinsky B. Non-contact monitoring of temporal volume changes of a hematoma in the head by a single inductive coil: a numerical study. IEEE T Bio-Med Eng. 2018;66(5):1328-36.

52. Oziel M, Korenstein R, Rubinsky B: A Brain Phantom Study of a Noncontact Single Inductive Coil Device and the Attendant Algorithm for First Stage Diagnosis of Internal Bleeding in the Head. Journal of Medical Devices. 2020; 14(1).

53. Oziel M, Rubinsky B, Korenstein R. Detection and estimating the blood accumulation volume of brain hemorrhage in a human anatomical skull using a RF single coil. PeerJ. 2020;8:e10416.

54. Oziel M, Hjouj M, Rubinsky B, Korenstein R. Multifrequency analysis of single inductive coil measurements across a gel phantom simulation of internal bleeding in the brain. Bioelectromagnetics. 2020;41(1):21-33.

55. Li G, Chen J, Gu S, Yang J, Chen Y, Zhao S, Xu J, Bai Z, Ren J, Xu L. A dual parameter synchronous monitoring system of brain edema based on the reflection and transmission characteristics of two-port test network. IEEE Access. 2019;7:50839-48.

56. Halstead MR, Geocadin RG. The medical management of Cerebral edema: past, present, and future therapies. Neurotherapeutics. 2019;16(4):1133-48.

57. Alruwaili F, Cluff K, Griffith J, Farhoud H. Passive self resonant skin patch sensor to monitor cardiac intraventricular stroke volume using electromagnetic properties of blood. IEEE J TransI Eng Health Med. 2018;6:1-9.

58. Mohammed N, Cluff K, Griffith J, Loflin B: A non-invasive wearable readout system for bio-fluid phenomena detection. In 2019 IEEE 16th International Conference on Wearable and Implantable Body Sensor Networks (BSN):2019. IEEE; 2019:1-4.

59. Mohammed N, Cluff K, Griffith J, Loflin B. A noninvasive, electromagnetic, epidermal sensing device for hemodynamics monitoring. IEEE T Biomed Circ S. 2019;13(6):1393-404.

60. Hui X, Kan EC. Monitoring vital signs over multiplexed radio by near-field coherent sensing. Nat Electr. 2018;1 (1):74.

61. Pan W, Yan Q, Qin M, Jin G, Sun J, Ning X, Zhuang W, Peng B, Li G. Detection of cerebral hemorrhage in rabbits by time-difference magnetic inductive phase shift spectroscopy. PLoS ONE. 2015;10(5):e128127.

62. Oziel M, Hjouj M, Gonzalez CA, Lavee J, Rubinsky B. Non-ionizing radiofrequency electromagnetic waves traversing the head can be used to detect cerebrovascular autoregulation responses. Sci Rep. 2016;6:21667.

63. Li G, Ma K, Sun J, Jin G, Qin M, Feng H. Twenty-four-hour real-time continuous monitoring of cerebral edema in rabbits based on a noninvasive and noncontact system of magnetic induction. Sensors. 2017;17(3):537.

64. Lin X, Chen Y, Gong Z, Seet B, Huang L, Lu Y. Ultra-wideband textile antenna for wearable microwave medical imaging applications. IEEE T Antenn Propag. 2020;68(6):4238-49.

65. Griffiths H, Stewart WR, Gough W. Magnetic induction tomography: a measuring system for biological tissues. Ann Ny Acad Sci. 1999;873(1):335-45.

66. Merwa R, Hollaus K, Biro O, Scharfetter H. Detection of brain oedema using magnetic induction tomography: a feasibility study of the likely sensitivity and detectability. Physiol Meas. 2004;25(1):347.

67. Gabriel S, Lau RW, Gabriel C. The dielectric properties of biological tissues: III. Parametric models for the dielectric spectrum of tissues. Phys Med Biol. 1996;41(11):2271.

68. Mestre H, Du T, Sweeney AM, Liu G, Samson AJ, Peng W, Mortensen KN, Stæeger FF, Bork PA, Bashford L. Cerebrospinal fluid influx drives acute ischemic tissue swelling. Science. 2020;367(6483):eaax7171. 
69. Chen J, Li G, Chen M, Jin G, Zhao S, Bai Z, Yang J, Liang H, Xu J, Sun J. A noninvasive flexible conformal sensor for accurate real-time monitoring of local cerebral edema based on electromagnetic induction. PeerJ. 2020;8:e10079.

70. Yang J, Zhao H, Li G, Ran Q, Chen J, Bai Z, Jin G, Sun J, Xu J, Qin M. An experimental study on the early diagnosis of traumatic brain injury in rabbits based on a noncontact and portable system. PeerJ. 2019;7:e6717.

71. Fujita S, Ueda T, Yagi M. Detection of experimental and clinical brain edema using an electrical impedance method. J Neurosurg. 1972;37(2):156-63.

\section{Publisher's Note}

Springer Nature remains neutral with regard to jurisdictional claims in published maps and institutional affiliations.

- fast, convenient online submission

- thorough peer review by experienced researchers in your field

- rapid publication on acceptance

- support for research data, including large and complex data types

- gold Open Access which fosters wider collaboration and increased citations

- maximum visibility for your research: over $100 \mathrm{M}$ website views per year

At BMC, research is always in progress.

Learn more biomedcentral.com/submissions 